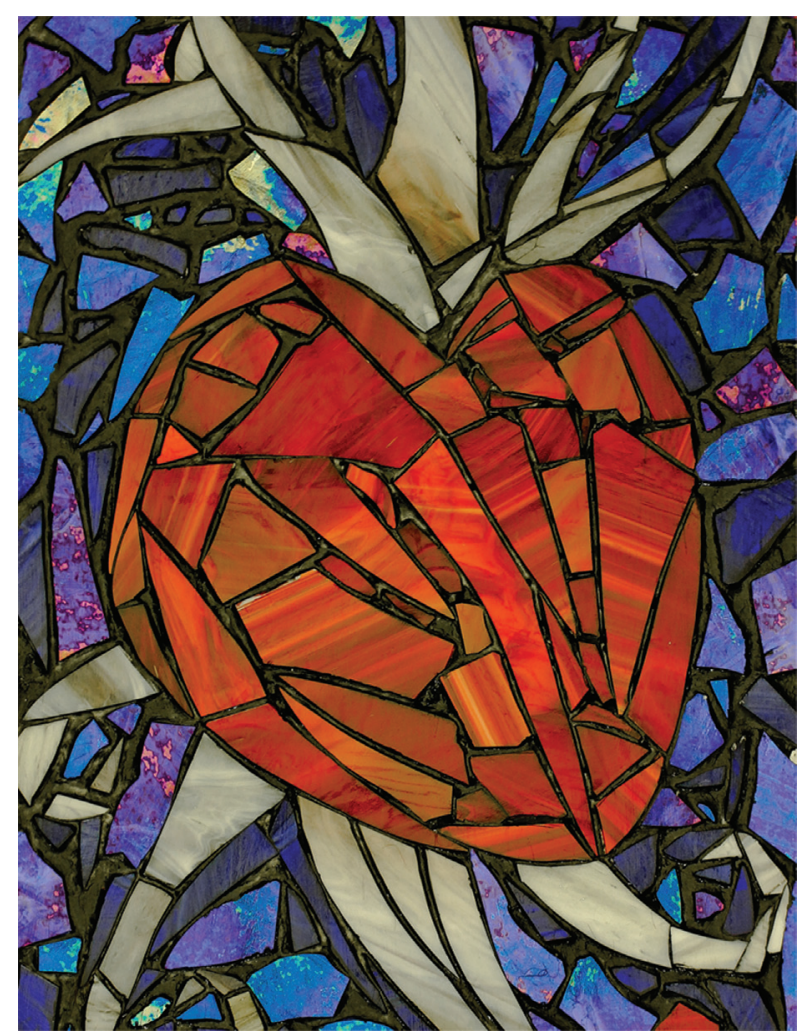

\title{
All Heart
}

\author{
Brittney M. Benjamin* \\ College of Human Medicine, Michigan State University, Grand Rapids, MI, USA \\ *Corresponding author: Brittney M. Benjamin; brittneymichellebenjamin@gmail.com
}

The Heart of a physician is a conduit.

T here has been a trend to portray doctors as "all" - all knowing, all thinking, all seeing, all doing. We're all brains, learning and memorizing, and all hands, cutting and suturing. Doctors can be any or none of these things, but sometimes we miss our greatest strength: we can be all Heart. And by being all Heart, we must be careful how our experiences affect us.

It is not a new idea to suggest life experiences determine who we are; every human being is just a sum of what is being poured into them. However, physicians have the unique privilege of affecting many other lives as well; our life experiences not only change us, but also determine how we will treat our patients. This is why a physician's Heart must be a conduit - it is our responsibility to transform our experiences so that we help rather than harm others.

Our good moments must be amplified; our bad moments must be tempered so that they can become strengths rather than weaknesses. How many times have pain and discrimination cycled through humanity simply because no one had the ability to transform that pain and break the cycle?

For me, my personal tragedies can be limiting, or they can help me better connect with patients going through their own pain. The love and support I have been shown along the way to medical school can either end with me, or can be nurtured so that I can be a lodestone for future patients.

As physicians, we have the opportunity to touch many lives, many Hearts. Let's not squander that opportunity. 